\title{
Resveratrol and Neuroprotection: Impact and Its Therapeutic Potential in Alzheimer's Disease
}

\begin{abstract}
Md. Habibur Rahman ${ }^{1 \dagger}$, Rokeya Akter ${ }^{2 \dagger}$, Tanima Bhattacharya ${ }^{3}$, Mohamed M. Abdel-Daim ${ }^{4,5 *}$, Saad Alkahtani ${ }^{4}$, Mohammed W. Arafah ${ }^{4}$, Norah S. Al-Johani ${ }^{4}$, Norah M. Alhoshani ${ }^{4}$, Nora Alkeraishan ${ }^{4}$, Alhanof Alhenaky ${ }^{4}$, Omar H. Abd-Elkader ${ }^{6}$, Hesham R El-Seedi ${ }^{7,8}$, Deepak Kaushik ${ }^{9}$ and Vineet Mittal ${ }^{9}$

${ }^{1}$ Department of Pharmacy, Southeast University, Banani, Dhaka, Bangladesh, ${ }^{2}$ Department of Pharmacy, Jagannath University, Sadarghat, Dhaka, Bangladesh, ${ }^{3}$ School of Chemistry and Chemical Engineering, Hubei University, Wuhan, China, ${ }^{4}$ Department of Zoology, College of Science, King Saud University, Riyadh, Saudi Arabia, ${ }^{5}$ Pharmacology Department, Faculty of Veterinary Medicine, Suez Canal University, Ismailia, Egypt, ${ }^{6}$ Physics \& Astronomy Department, Science College, King Saud University, Riyadh, Saudi Arabia, ${ }^{7}$ International Research Center for Food Nutrition and Safety, Jiangsu University, Zheniiang, China,

${ }^{8}$ Pharmacognosy Group, Department of Pharmaceutical Biosciences, Uppsala University, Uppsala, Sweden, ${ }^{9}$ Department of Pharmaceutical Sciences, Maharshi Dayanand University, Rohtak, India
\end{abstract}

Edited by:

Ashok Kumar,

University of Florida, United States

Reviewed by:

Yona Levites,

University of Florida, United States Faheem Hyder Pottoo,

Imam Abdulrahman Bin Faisal

University, Saudi Arabia

*Correspondence:

Mohamed M. Abdel-Daim

mabdeldaim.c@ksu.edu.sa

${ }^{\dagger}$ These authors have contributed equally to this work

Specialty section:

This article was submitted to

Neuropharmacology,

a section of the journal

Frontiers in Pharmacology

Received: 19 October 2020 Accepted: 07 December 2020 Published: 30 December 2020

Citation:

Rahman MH, Akter R, Bhattacharya T, Abdel-Daim MM, Alkahtani S,

Arafah MW, Al-Johani NS,

Alhoshani NM, Alkeraishan N,

Alhenaky A, Abd-Elkader OH,

El-Seedi HR, Kaushik $D$ and Mittal $V$

(2020) Resveratrol and

Neuroprotection: Impact and Its

Therapeutic Potential in

Alzheimer's Disease.

Front. Pharmacol. 11:619024.

doi: 10.3389/fphar.2020.619024
Alzheimer's disease (AD) is a progressive cortex and hippocampal neurodegenerative disease which ultimately causes cognitively impaired decline in patients. The AD pathogen is a very complex process, including aggregation of $A \beta$ ( $\beta$-amyloid peptides), phosphorylation of tau-proteins, and chronic inflammation. Exactly, resveratrol, a polyphenol present in red wine, and many plants are indicated to show the neuroprotective effect on mechanisms mostly above. Resveratrol plays an important role in promotion of non-amyloidogenic cleavage of the amyloid precursor protein. It also enhances the clearance of amyloid beta-peptides and reduces the damage of neurons. Most experimental research on AD and resveratrol has been performed in many species, both in vitro and in vivo, during the last few years. Nevertheless, resveratrol's effects are restricted by its bioavailability in the reservoir. Therefore, scientists have tried to improve its efficiency by using different methods. This review focuses on recent work done on the cell and animal cultures and also focuses on the neuroprotective molecular mechanisms of resveratrol. It also discusses about the therapeutic potential onto the treatment of AD.

Keywords: Alzheimer's disease, resveratrol, oxidative stress, neuroprotective, therapeutic agent, bioavailability

\section{INTRODUCTION}

Alzheimer's disease (AD) induces executive control and memory loss, a neurodegenerative disorder of the brain. It also affects long-term declarative memory and working memory of the patient. It correlates with the functional and structural parameters of the brain. It works on the pathology of formation of memories from the framework and molecular level of neural networks. Dementia also occurs in ageing stage due to the presence of Alzheimer's disease (Kelley and Petersen, 2007; Jahn, 2013). While AD was established more than 100 years ago, attempts are now being made to find new chemical products (i.e., natural antioxidants) that function at different points to avoid the progression of this disease. After studying of human experimental and accumulating data, it concludes that the pathogenesis of $\mathrm{AD}$ caused by the process of oxidative stress (OS) is produced from reactive oxygen species (ROS). This process takes place before appearing the 
molecular events (neurofibrillary tangles and $\beta$-amyloid plaques) and symptoms of $\mathrm{AD}$. It also leads to damage of tissue by several pathways of various cellular molecules present into the neuron. The process of damage of cellular components like proteins, lipids, and nucleic acids (like RNA and DNA) caused by ROS leads to death of cells by apoptosis and necrosis process. After weakening of cellular antioxidant defense system, more damage of cells takes place. With the help of antioxidants, there can be prevention of tissue damage, and it also improves both neurological and survival outcomes (Gilgun-Sherki et al., 2003; Feng and Wang, 2012). The pathogenesis and development of AD are not well understood. However, neuronal loss, synaptic interconnections, and glial proliferation are widely studied, including neurotic plaques (senile plaques) (Selkoe, 2001). Thus, while the explanations for $\mathrm{AD}$ remain doubt, two commonly identified pathological features remain, senile plaque (SPs) and neurofibrillary tangles (NFTs). The SPs are the $\beta$-amyloid (A $)$, a dystrophic neuritis nucleus, activated by astrocytes, and microglia. NTFs consist of hyperphosphorylation and abnormal tau protein deposition. According to a study, it shows that by using resveratrol, we can easily slow down the effect of $\mathrm{AD}$. The neuroprotective nature of resveratrol takes place by inhibiting $A \beta$ ( $\beta$-amyloid) aggregation, by exerting antiinflammatory activity and by scavenging oxidants. The neuroprotective action of resveratrol in neuroblastoma cells of human, exposed to $A \beta$-metal complex or $A \beta$ (Granzotto and Zatta, 2011). For a long time, scientists have sought to diagnose and mitigate cognitive conditions. Unfortunately, there has not been any reversal of current deficits or disease progression treatment at present. In another study, results show that when patients of $\mathrm{AD}$ are treated with omega-3 fatty acid docosahexaenoic acid (DHA), the symptoms of $\mathrm{AD}$ seem moderate to mild in patients (Yaffe, 2010). Many other treatments with several drugs have been widely used to alleviate symptoms of $\mathrm{AD}$, including some inhibitors of cholinesterase and, in the meantime, a glutamate antagonist $\mathrm{N}$-methyl D-aspartate form (NMDA) receptor. However, the complex mechanisms have shown that these compounds produce a range of side effects and relatively small benefits (Allain et al., 2003). For instance, cholinesterase inhibitors can have temporary and modest effects on memory loss and motor function improvements, but side effects such as nausea and diarrhea are typically intolerable (Kim et al., 2010). In clinical trials, tacrine, another cholinesterase inhibitor, was reduced into low oral bioavailability and significant hepatotoxicity. In the meantime, a hoping drug has proven to have less clinical success than the cholinesterase inhibitors (Kim et al., 2010). Resveratrol is a natural compound obtained from plants that occurs primarily in grapevine and other fruit specie. Its diverse biological characteristics including antioxidant, antiinflammatory, and neuroprotective activities attract wide attention. Resveratrol may indirectly activate the expression of SIRT1 and leads to AD neuroprotection (Beher et al., 2009). Resveratrol (3, 5, 4'-trihydroxy-trans-stilbene) is a kind of polyphenol produced in several plants, especially from grapes skin and seeds, and acts as a phytoalexin against pathogens like bacteria or fungi (Li et al., 2012). Resveratrol has demonstrated diverse biological activities in the treatment of cardiovascular and cancer, as well as revenant disorders, including brain diseases and $\mathrm{AD}$, and produces protective effects such as antioxidants, antimicrobial, phytoestrogenic, vasorellaxant, cardioprotection, and anticancer (Baur et al., 2006; Holland et al., 2008; Oomen et al., 2009). Many studies were carried out to find out whether resveratrol can take on the therapeutic potential for $\mathrm{AD}$ and other neurodegenerative diseases. However, the long-term effects of human supplementation are still under investigation, including resveratrol and $\mathrm{AD}$. The studies show that resveratrol has taken part in many pathophysiological AD courses (Baur and Sinclair, 2006). Recent studies on cell cultures, animal models, and primarily on the molecular mechanisms of neuroprotective effects of resveratrol are explored in this review, and the therapeutic potential of the disease is investigated. We also address the role of resveratrol in $\mathrm{AD}$ therapy, and it also discusses the possible benefits of resveratrol as a medical agent known as anti-AD.

\section{Specific Pathogens and Various Treatment Targets}

The exact mechanism of $\mathrm{AD}$ is unclear, but the compound resveratrol shows antioxidant activity on SIRT1 (silent information regulator-1) and it also causes neuronal differentiation. The growth of neurons highly dependent upon SIRT1 that is also responsible for prevention of apoptosis death in neurons. Pathogenic mechanisms of $\mathrm{AD}$ are very complex; it includes $A \beta$ accumulation, oxidative stress, tau protein phosphorylation, and inflammation (Figure 1). In this case, most therapies cannot consider every aspect. AD describes pathological properties, especially neuritis and NFTs that are visible in AD patients' brains by microscopy (Perl, 2010). The presence of $A \beta$ ( $\beta$-amyloid peptides) is widely responsible for learning and memory ability of AD. By inhibiting the process of $\mathrm{A} \beta$ peptide aggregation, we can easily treat the disease of $\mathrm{AD}$. Neurotic plaques are $A \beta$ peptide extracellular insoluble deposits, which are also identified as senile plaques. In 1992, an amyloid discovery was concluded that $A \beta$ accumulation was the key cause of $\mathrm{AD}$, and the hypothesis has since been gradually recognized (Hardy, 2006). Amyloid precursor protein (APP) is abnormally cleavage by $\beta$ - and $\gamma$-secretase (not $\alpha$-secretase), leading to an unnecessary cortex-hippocampal extracellular $A \beta$ accumulation in brains. The buildup of $A \beta$ contributes to progressive neuronal failure, neural circuit interdiction, and $A D$ neurological characteristic deterioration. Several investigations occur with $\mathrm{AD}$ therapies, along with clinical trials that block pathogenic amyloid- $\beta$ peptides. It also rescues vulnerable neurons from the process of degeneration (Roberson and Mucke, 2006). However, APP is separated by the $\alpha$-secretase pathway into soluble amyloid a precursor $\alpha(\mathrm{sAPP} \alpha)$, which may reduce the generation of $\mathrm{A} \beta$ and protect the neurons relatively by fostering axon growth. Consequently, the principal goals of $\mathrm{AD}$ products are $\beta$ - and gamma-secretase, but $\alpha$-secretase improvement can also have the same anti-AD therapy effect.

Oxidative stress has been particularly affected by the pathogenesis of neurodegenerative diseases such as $\mathrm{AD}$ and 


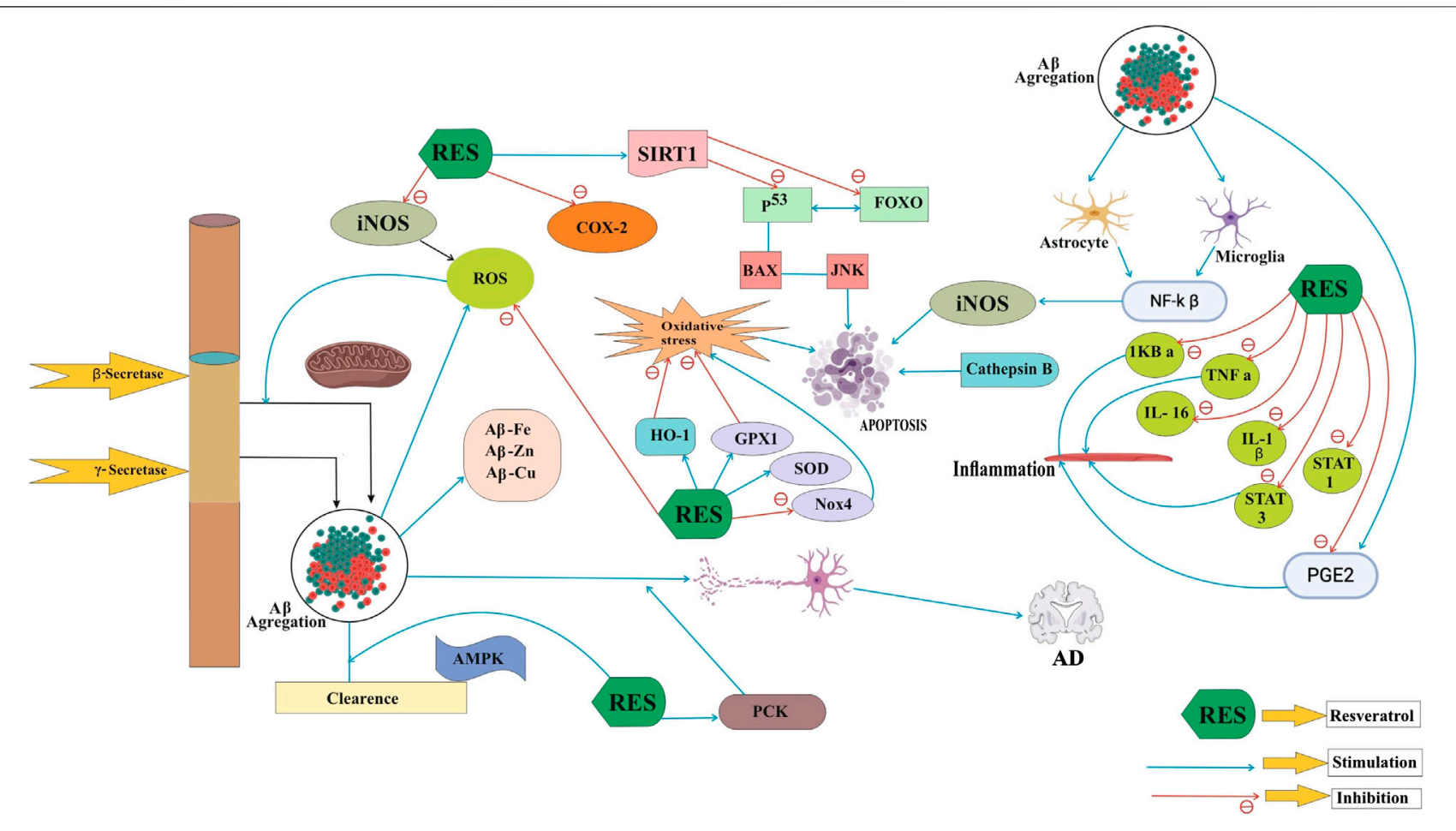

FIGURE 1 | Neuroprotective functions of resveratrol in AD pathogenesis.

has become extremely susceptible to oxidative damage because of the greater degree of polyunsaturated grain and the relative lack of antioxidant role in other organisms. As we can see, in case of Alzheimer's disease (AD), there is an increasing level of proteins, oxidized nucleic acid, and lipids. It is quite resemblance with Down's syndrome in young adults. The process of cellular damage and oxidative stress (OS) takes place in early stage of AD. Several anti-inflammatory agent, antioxidants, mitochondrial protective agents, and metal chelators are used against $\mathrm{OS}$ therapies for $\mathrm{AD}$. Some of them show neuroprotective effect against animal and cellular models of AD (Nunomura, 2013). The generation of damaged mitochondria during oxidative stress, primarily by nitrogen oxide synthase (iNOS) and cyclooxygenase-2, leads to injury, loss of membrane integrity, and a loss of lipid peroxidation and nuclear acids. ROS increasing $\mathrm{A} \beta$ production, and $A \beta$ inducing oxidative stress, a vicious circle between ROS and $A \beta$ accumulation, may accelerate the progression of AD (Li et al., 2012). The ROS increases AD development, $A \beta$ growth, and the oxidative stress caused by $\mathrm{A} \beta$, a brutal process between the accumulation of ROS and $A \beta$ (Li et al., 2012). Resveratrol is used to not only minimize iNOS concentrations and lipid peroxidation in neuronal cells as an antioxidant but also increase hemoxidation production-1 (HO-1) to prevent oxidation. Neuroinflammation recently showed that it contributes significantly to $\mathrm{AD}$ pathogenesis (McGeer and McGeer, 2003). Flammative changes in the $\mathrm{AD}$ brain, particularly in the amyloid deposits, including microglia activation, astrocytes, and macrophages, can be observed. The changes like neuroinflammation observed in the several affected areas of the brain combines with epidemiological evidence that produces protective effect of anti-inflammatory agents which may play an important role in treating $\mathrm{AD}$ (McGeer and McGeer, 2003). Many data in cell and mouse cultures indicate that aggregated $A \beta$ is responsible for activating and releasing astrocytes and microglia, leading to the release of significant quantities of inflammatory mediators including cytokines, free radicals, and nitric oxide (NO)(Capiralla et al., 2012; Tansey et al., 2007; Velez-Pardo et al, 2002). A $\beta$ triggers the respiratory burst of microglia and produces ROS and tumor necrosis factor-alpha (TNF- $\alpha$ ), which aggravates $A \beta$ deposition and further neuronal dysfunction and eventual death (Holtzman, 2008; Wilcock et al., 2009). Synaptic dysfunction takes place during the early stage of $\mathrm{AD}$, and synapse failures are found during the later stage. The hippocampus and stroke impede excitatory transmission, leading to loss of memory (Selkoe, 2002; Mallucci et al., 2007). While A $\beta$ deposition can lead to neuronal loss, apoptosis is the principal method of neuronal synapse loss. Multiple factors, such as stress, glucose metabolism, and mitochondrial excitotoxic damage, may trigger apoptosis in $\mathrm{AD}$ models. In the apoptosis cycle of $\mathrm{AD}$, other substrates such as p53, FOXO, and ROS are involved. There seems to be a possible treatment of $\mathrm{AD}$ for apoptosis downregulation.

Tau protein is a highly soluble, microtubule-associated protein (MAP). Some of these protectors reside in central and peripheral neurons and act as stabilizers of microtubules. Deposition of tau hyperphosphorylation and amyloid- $\beta$ is a cardinal pathologic feature of $\mathrm{AD}$ which leads to the formation of neurofibrillary tangles and neuronal plaques. Herbal compound like resveratrol 
TABLE 1 | Neuroprotective effects of resveratrol in vivo.

\begin{tabular}{|c|c|c|c|}
\hline Animal model & Administration category & Effects & Reference \\
\hline C57Bl/6 mice & Resveratrol in food & $\begin{array}{l}\text { (1) Increasing microvascular density and lower vacuolar anomalies. (2) } \\
\text { Improved efficiency in spatial orientation and memory. }\end{array}$ & Oomen et al. (2009) \\
\hline Tg2576 mice & $\begin{array}{l}\text { Cabernet Sauvignon to } \\
\text { drink }\end{array}$ & Reduced amyloid neuropathology and loss of visual memory. & Wang et al. (2006) \\
\hline C67BL/6J mice & $\begin{array}{l}\text { Trans-resveratrol diet } \\
\text { every day }\end{array}$ & Serum TNF-a decreased and cognitive function increased. & Jeon et al. (2012) \\
\hline Tg2576 mice & Feeds on GPSE & Decreased $A \beta$ peptide oligomerization and decreased cognitive deficits. & Wang et al. (2008) \\
\hline APP/PS1 mice & Resveratrol diet & Decreased the amount of microglia activated. & Capiralla et al. (2012) \\
\hline C57BI/6J mice & Food resveratrol & $\begin{array}{l}\text { Improved mitochondrial activity, aeroplane ability increased, and } \\
\text { sensorimotors strengthened. }\end{array}$ & Lagouge et al. (2006) \\
\hline Male mice, 2 months old. & i.p. injection of resveratrol & The AMPK in the brain is activated. & $\begin{array}{l}\text { Dasgupta and } \\
\text { Milbrandt (2007) }\end{array}$ \\
\hline Wistar Councils, i.p. STZ injector & i.p. injection of resveratrol & This makes cholinergic neurotransmission easier for users to understand. & Schmatz et al. (2009) \\
\hline $\begin{array}{l}\text { Consequences, ICV colchicine } \\
\text { administration }\end{array}$ & $\begin{array}{l}\text { Chronic resveratrol } \\
\text { treatment (P.O.) }\end{array}$ & The level of MDA decreased but the activity of GSH and AchE recovered. & Kumar et al. (2007) \\
\hline Sprague-Dawley rat & Oral resveratrol & The effects of resveratrol can be positive on BDNF expression. & Banerjee et al. (2008) \\
\hline Inducible p25 transgenic mice & Resveratrol ICV injection & $\begin{array}{l}\text { Reduces hippocampal neurodegeneration and prevents cognitive } \\
\text { deterioration. }\end{array}$ & Kim et al. (2007a) \\
\hline
\end{tabular}

is highly responsible for anti-AD effect into the brain (Villaflores et al., 2012). Tau is a phosphoprotein that is regulated by several kinases in the phosphorylation of tau. If the tau protein has a phosphorylated material, it derives abnormally, like $\mathrm{AD}$, from microtubules and aggregates (Alonso et al., 2001). The phosphorylated tau protein disassembles neurofibrillary engravings in microtube and aggregates, the distinctive characteristic of $\mathrm{AD}$ pathology. When tau is polymerized as neurofibrillary tangles, it loses its connection to the tubulin and the microtubules. Hence, inhibition of tau pathological hyperphosphorylation may be a therapeutic target for $\mathrm{AD}$ as well as other disorders (Alonso et al., 2008; Iqbal et al., 2010). The therapies for many incremental neurodegenerative disorders, such as Huntington disease, Parkinson's disease, and AD, were neurological problems. Resveratrol has strong metabolic effects and is considered an example of caloric limitation (Pasinetti et al., 2011). Resveratrol has shown neuroprotective effects on pleiotropic functions in recent years. In general, studies demonstrate that in different models, both in vitro and in vivo, resveratrol has significant neuroprotective properties (Saiko et al., 2008). According to Kores et al, it is believed that resveratrol is an important constituent to cure neurological disorder like Alzheimer's disease and cardiovascular disorders. By using the molecular docking approach, it is concluded that new potential were found to targets of resveratrol. The results concluded that more than three human proteins are already known to bind with resveratrol. A large number of protein were discovered by this docking process which connects to resveratrol. It leads to a new possibility to cure a variety of disease like AD (Kores et al., 2019). According to Rong Ma et al, the diseases such as Alzheimer's disease (AD) and diabetes mellitus (DM) mostly coexist in the patients. Due to the conditions of one disease, there is an increasing risk of another one. Both diseases have the same pathophysiological mechanism, oxidative stress, inflammatory signaling pathways, and cell apoptosis. The level of $A \beta$ also similarly elevates into the brain. By using compound resveratrol, both diseases DM and AD can be treated simultaneously by modulating oxidative stress and by reducing inflammation into the brain (Ma et al., 2019). According to Chen et al, resveratrol shows positive results in animal models of $\mathrm{AD}$. There are a number of theories on the mechanism of action of resveratrol. By using rodent AD models, the efficacy of resveratrol was studied. The analysis of results shows that resveratrol is highly effective as a neuroprotective agent. It includes some clinical trial on the studies of treatment of AD (Chen et al., 2019). According to Yan et al, due to ageing of population, the number of cases of $\mathrm{AD}$ increases in the society. Various phytochemicals have been used for the treatment of $\mathrm{AD}$, from which resveratrol is one of them. There is a possible relationship between $\mathrm{AD}$ and factors like glutamine receptors (AMPARs), synapses, estrogens, and silent information regulator 1 (SIRT1). Treatment of $\mathrm{AD}$ with resveratrol compound is highly demanding among all of them (Yan et al., 2020).

\section{Resveratrol: Neuroprotective Effects in vivo}

In animal models, particularly in rat models, resveratrol was found to be neuroprotective (Table 1 ). The routine moderate consumption of red wine reduces amyloid-AD neuropathology substantially and mitigates the $A \beta$-associated mouse memory loss Tg2576 (Wang et al., 2006). Recent studies about Tg2576 mice indicated that extracellular accumulation of soluble $\mathrm{A} \beta$ oligomers was largely responsible for AD dementia and memory deficits (Cleary et al., 2005). Treatment with polyphenolic compounds from grape seed extract (GPSE) decreased A $\beta$ peptide oligomerization and decreased amyloid Tg2576 mice's cognitive loss (Wang et al., 2008). In the treatment of resveratrol APP/PS1 mice, the amount of activated microglia decreases considerably and indicates that resveratrol decreases in part inflammation, regardless of its effects on amyloid deposition (Jeon et al., 2012). Studies in a C57Bl/6J mice model have also shown that the number of rears in highgrade mice treated with resveratrol has decreased substantially in ambulatory locomotives operation and is 
likely to decrease ((Lagouge et al., 2006). The findings showed that the resveratrol effect on both muscle and brown adipose tissues could increase mitochondrial activity, resulting in greater consumption of energy, greater aerobic efficiency, and increased sensorimotor function (Lagouge et al., 2006). Sharma and Gupta indicated that ICV STZ group rats chronically treated with trans-resveratrol showed significantly increased retention latencies and shorter transfer latencies on the elevated plus-maze, but no significant difference in the locomotor activity of sham. A study was conducted on the intracerebroventricular (ICV) streptozotocin (STZ) model of various types of rats having dementia of Alzheimer's type. The compound resveratrol produces effect on ICV STZ in rats. These were treated with 10 and $20 \mathrm{mg} / \mathrm{kg}$ dose of resveratrol for 21 days. A rising of brain glutathione and an increasing level of MDA (malondialdehyde) in the brain treated with ICV STZ is observed in rats. So it concludes that it is possible to cure neurodegenerative disease like AD with resveratrol (Sharma and Gupta, 2002). Some rat models used colchicine in ICV (15 $\mu \mathrm{g} /$ $5 \mu \mathrm{l})$ that can cause cognitive impairment. The level of malondialdehyde (MDA) and nitrite decreased the activity of glutathione, acetylcholinesterase improved, and colchicine cognitive impairment increased significantly for 25 days (Kumar et al., 2007). Additionally, resveratrol therapies in diabetic rats may avoid increased AChE behaviors in cholinergic neurotransmission, which can then increase cognitive dysfunction, and boost cognition (Schmatz et al., 2009). In the analysis, brain-derived neurotrophic factor (BDNF) mRNA of the hippocampal Sprague-Dawley rat model was stimulated by oral resveratrol. The BDNF has similar functions such as resveratrol, and the study has shown that resveratrol can support BDNF expression (Rahvar et al., 2011). The SIR2 genes promote the reproduction of many animals and the benefits for the well-being of calorie reduction of SIR2 genes. SIRT1, one of seven NAD + mammals, has recently been shown to aid cellular regulation and to participate in many SIRT1 signal pathways (Bonda et al., 2011). The resveratrol ICV injection used the transgenic p25 mouse, AD pattern, and tauopathies to activate the SIRT1. In vehicle-treated animals, the cell death and neurodegeneration were evident after five weeks of induction of P25, but resveratrol administration was effective in reducing CA1 and CA3 hippocampal neurodegeneration by lower apoptotic marker-activated caspase-3 markers and the glial fibrillary acid (GFAP) (Kumar et al., 2007). P25-green fluorescent protein that expresses neurons showed that p25 can withstand and thrive on the hippocampus of resveratroltreated rats. After 3 weeks of resveratrol therapy, learning capacity improved. This means that resveratrol offers neuroprotection and prevents animal models from slipping in cognitive stages (Kim et al., 2007a). In animal neurodegenerative disorders triggered by certain neurotoxicity, resveratrol is useful. The antioxidants and anti-inflammatory properties of the possible pathways can be responsible. Resveratrol pretreatment significantly reduces oxidative stress injury and improves motor and cognitive injury (Kumar et al., 2006; Zhang et al., 2010).

\section{Resveratrol: Neuroprotective Effects In Vitro}

For several in vitro models as a rat or human cells, neuroprotective effects of resveratrol have been observed (Table 2). In 10-day Sprague-Dawley rat pups, glutamate easily triggered the production of monocyte chemical protein 1 (MCP-1). Resveratrol downregulated glutamate-induced extracellular signal-regulated kinase (ERK) activation and then resulted in decreased interleukin-1 $\beta$ (IL-1 $\beta$ ) expression and the subsequent downregulation of MCP-1 in the hippocampus (Lee et al., 2010). There was a decrease in 1a-receptor-gammacoactivator-(PGC-) proliferator-activated peroxisome in rats that indicated an increase in SIRT1 following primary resveratrol therapy. Higher SIRT1 levels were also correlated with protective functions of neurotoxicity of p25 or mutant SOD1 in the primary neurons. Resveratrol assisted neuroprotection and avoided cognitive decline with deacetylation of p53 and thereby reduced p53, an important cell death mediator (Kim et al., 2007a). The inhibition of intracellular calcium and ROS output has been found to prevent neuronal death caused by the NMDA (Ban et al., 2008). A $\beta 25-35$ was taken to determine neuronal cell death from $A \beta$ due to their similar toxic action mechanism in a study of primary hippocampal cultured cells. Dose-mediated cell death dependent on $A \beta$ 25-35 decreases pretreatment resveratrol $(15-40 \mu \mathrm{M})$ substantially, with a median effect of $25 \mu \mathrm{M}$, on hippocampal neuronal cells. In the meantime, treatment with resveratrol and posture had similar neuroprotective effects, although the findings were slightly lower in severity (Han et al., 2004). Protein kinase C (PKC), with a median effect of $20-30 \mu \mathrm{M}$ and based on dosage, was phosphorylated by the resveratrol induce. The effects of resveratrol on PKC- $\alpha / \beta I I$, PCC- $\mu$ (Ser 916), and PKC-Ther were also substantially reduced. This indicates that the neuroprotection effects of P K-D (Thr505) affect resveratrol. In short, the PKC pathway had a significant role in the neuronal hippocampal toxicity of resveratrol (Han et al., 2004). NO donor SNP $(100 \mu \mathrm{M})$ therapy in mixed cells (glial) and neuronal cells resulted in resveratrol and cell survival damage $(5 \pm 25 \mu \mathrm{M})$ and the median concentration of $5 \mu \mathrm{M}$ and the average concentration $(25 \mu \mathrm{M})$ investigated this survival gain. Resveratrol and other polyphenols from red wine were activated by possible antioxidant activities to save hippocampal cells from NO toxicity. Note: the effects on intracellular enzymes including COX/LOX, NOS, and PKC were not included because quercetin did not include this experiment. However, in lipopolysaccharideactivated macrophages, resveratrol $(10 \mu \mathrm{M})$ was found to enhance NO generation and the suppression of iNOS. Different factors such as cell types and medicaments can lead to it (Bastianetto et al., 2000). Multi-accident regulation in COX/PGE2 can also inhibit the free formation and free radical formation of prostaglandin E2 (PGE2) in the primary microglial cultivated cells by active microglia cells. The LPS-media prostaglandin E synthase-1 (mPGES-1) and COX-1 expression can be reduced, but not COX-2 (Candelario-Jalil et al., 2007). A $\beta$ has contributed to time-dependent cell growth in cultured rat astroglioma $\mathrm{C} 6$, but resveratrol pretreatment protects cellulose against $A \beta$ toxicity. In 
TABLE 2 | Neuroprotective effects of resveratrol in vitro.

\begin{tabular}{|c|c|c|c|}
\hline Types of cell & Exposure & Effects of resveratrol & Reference \\
\hline $\begin{array}{l}\text { Primary cortical } \\
\text { neurons }\end{array}$ & Exposure to NMDA & Hampered the intracellular calcium elevation and ROS output. & $\begin{array}{l}\text { Ban et al. } \\
(2008)\end{array}$ \\
\hline $\begin{array}{l}\text { Primary hippocampal } \\
\text { cells }\end{array}$ & $A \beta_{25-35}$ induced & Reduced cell death by A $\beta$ 25-35, and phosphorylation was reduced by PKC- $\beta$. & $\begin{array}{l}\text { Han et al. } \\
\text { (2004) }\end{array}$ \\
\hline $\begin{array}{l}\text { Rat cortical primary } \\
\text { neurons }\end{array}$ & $\begin{array}{l}\text { lonomycin and } \\
\mathrm{H}_{2} \mathrm{O}_{2} \text { diagnosis }\end{array}$ & Increased development of SIRT1, and cognitive decrease prevention. & $\begin{array}{l}\text { Kim et al. } \\
\text { (2007a) }\end{array}$ \\
\hline $\begin{array}{l}\text { Mixed (glial/neuronal) } \\
\text { hippocampal cells }\end{array}$ & $\begin{array}{l}\text { Treated with SNP or } \\
\text { SIN-1 }\end{array}$ & $\begin{array}{l}\text { Rescued hippocampal cells against NO-induced toxicity and inhibited NO generation and suppressed } \\
\text { iNOS in LPS-activated macrophages. }\end{array}$ & $\begin{array}{l}\text { Bastianetto } \\
\text { et al. (2000) }\end{array}$ \\
\hline $\begin{array}{l}\text { Hippocampal cells of } \\
\text { the murine HT22 and } \\
\text { primary cells of the } \\
\text { hippocampal }\end{array}$ & $\begin{array}{l}\mathrm{A} \beta, \mathrm{MEL} \text { and } \\
\text { resveratrol are } \\
\text { treated }\end{array}$ & $\begin{array}{l}\text { MEL and resveratrol had inhibited activation of ERK, decreased development of ROS, rescued GSH, and } \\
\text { reduced neuronal cell death. The synergistic effect of co-treatment. }\end{array}$ & $\begin{array}{l}\text { Kwon et al. } \\
(2010)\end{array}$ \\
\hline $\begin{array}{l}\text { Rat astroglioma C6 } \\
\text { cells }\end{array}$ & $A \beta$ is classified & $\begin{array}{l}\text { Reduced production of NO and iNOS expression, inhibited PGE2accumulation, decreased the COX- } \\
2 \text { expression, and prevented NF- } \mu \text { B from being translocated. }\end{array}$ & $\begin{array}{l}\text { Kim et al. } \\
(2006)\end{array}$ \\
\hline PC12 cells & $A \beta$ is classified & A $\beta$-soluble oligomers and conformers of the fibrillar remodels into large, nontoxic aggregates. & $\begin{array}{l}\text { Ladiwala et al. } \\
\text { (2010) }\end{array}$ \\
\hline SK-N-SH cells & IL-1 $\beta$ stimulated & Reduced development of PGE2 and PGD2 by COX-2 reduction. & $\begin{array}{l}\text { Ramesh et al. } \\
\text { (2009) }\end{array}$ \\
\hline $\begin{array}{l}\text { HUVEC-derived } \\
\text { EA.hy926 cells }\end{array}$ & DMNQ-induced & Reduced Nox4 expression, but enhanced SOD1 and GPx1 expression. & $\begin{array}{l}\text { Spanier et al. } \\
\text { (2009) }\end{array}$ \\
\hline
\end{tabular}

response to $\mathrm{A} \beta$ in these experiments, resveratrol inhibited concentration-dependent NO-output and iNOS expression. Besides, the inhibitory role of $A \beta$ aggregation of COX-2 in PGE2 C6 cells is shown in resveratrol. Alternatively, the A $\beta$ translocation of NF- $\kappa \mathrm{B}$ was disrupted by resveratrol before treatment (Kim et al., 2006).

The RAW 264.7, BV-2, and the Ba/F3 pro-B cell line, the murine microglial cells, have been recently studied. The treatment of resveratrol was found to be substantially reduced in LPS-started RAW 264.7, and BV-2 cells including IL-6, M-CSF, CD54, IL-1ra, and TNF- $\alpha$. All of them were regulated with NF-SB transcriptionally. The NF-SB reporting regulates the expression of the toxic factors of apoptosis iNOS and c cathepsin B. In RAW 264.7 and BV-2 the phosphorylated levels in IKKa, Ia, and NF- $\alpha$ decreased, while activation in Toll-like receptor (TLR) 4 was significantly inhibited by the phosphorylation of the Act, MyD88, and mediated kinase. On the other hand, resveratrol inhibited the STAT 1 and LPS activation of these two cell lines for signal transducers and transcription activators (STATs) and decreased dosage-dependent expression for iNOS or COX-2. Cytotoxicity-protected effect of resveratrol was shown to be A $\beta 25-35$ or A $\beta$ 1-42 in cultured rat pheochromocytoma cells (PC12). In this sense, this phenolic compound displayed morphology and increased TUNEL positive cells, also being found to inhibit controlled, apoptotic cell death $A \beta$ 25-35. It was reported to affect the A $\beta$ 25-35 activated apoptotic signaling pathways. These include preventing PARP cleavage, recovering reduced Bcl-XL expression, preventing Bax protein levels, blocking JNK-like phosphate activation, and removing

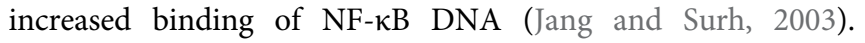
Resveratrol has also been found to dose-dependently restructure $A \beta$ soluble oligomers and fibrillar conformers in rat PC12 cells (Ladiwala et al., 2010). Many candidates who were active in antioxidant $\mathrm{AD}$ and neuroprotection were observable melatonin (N-acetyl-5-methoxy-tryptamine, MEL).
Co-treatments of MEL and resveratrol were more successful for $A \beta$ 1-42 mediated neurotoxicity with the culturally cultivated murine hippocampal and primary hippocampal neuron cells. MEL and resveratrol have inhibited ERK activation, reduced ROS production, rescued glutathione (GSH) concentrations, and decreased neuronal cell mortality. A rise in gsk $3 \beta$ activities and AMPK activation induced by $A \beta$ 1-42 were either inhibited by MEL or by resveratrol alone, and were synergistic with their co-treatment (Kwon et al., 2010).

Other liners of human cells are used to investigate the protective effects of resveratrol in $\mathrm{AD}$ (Table 2) also to rat cells as in vitro models. For example, the cell HEK293 was used to efficiency resveratrol on $A \beta$ clearance, by using the cell line originally derived from human embryonic kidney cells cultivated with human APP695. Resveratrol had no impacts on $\alpha$-, $\beta$-, or $\gamma$-medium APP-clips that did not influence the metabolism of the consumer and the development of resveratrol. Moreover, resveratrol was found in the sample. In HEK 293 cells, resveratrol failed, however, to promote intracellular proteasome-related clearing via $\mathrm{A} \beta$ without increasing the complete proteasome role by promoting the neutral endopeptidase (NEP), ECE-1, and ECE-2 by a $\beta$ - or insulin-degrading enzyme (Marambaud et al., 2005). In addition, the antioxidant effect of the human umbilical vein endothelial cells (HUVEC), resveratrol regulated the gene expression of pro-oxidant and antioxidant enzymes. Incubation of human umbilical vein endothelial cells (HUVEC) and HUVEC-derived EA.hy 926 cells with resveratrol resulted in a concentration- and time-dependent downregulation of Nox4, the most abundant NADPH oxidase catalytic subunit (quantitative real-time RT-PCR). The same resveratrol regimen upregulated the mRNA expression of SOD1 and GPx1. Resveratrol has provided a new approach to reducing endothelial oxidative stress (Spanier et al., 2009). In human hippocampus slices, resveratrol can bind directly to both 
monomeric and fibrillar amyloid structures so that resveratrol can specifically stain $A \beta$ plaques (Ge et al., 2012). Neuroblastoma cells SH-SY5Y were used to research the resveratrol inhibitory role of oligomeric cytotoxicity. Resveratrol has been shown to play a protective role in $\mathrm{AD}$ by eliminating the extension and disaggregating of $A \beta 42$ fibrils, but without inhibiting the formation of $A \beta 42$ oligomers (Feng et al., 2009). SH-SY5Y resveratrol activities in the metabolism of $A \beta$ have been found in the presence or lack of resveratrol in human neuroblastoma cultures treated with $\mathrm{A} \beta$ complexes. Resveratrol was not directly anti-amyloidogenic and destabilizing fibril but played an important role in the neuroprotection of complexes of $A \beta$ and $A \beta$-metals. Resveratrol, and its toxicity, scavenger $A \beta-F e$ and $A \beta$ $\mathrm{Cu}$ ROS generation after generation. Also, resveratrol effects have been studied in SK-N-SH cells in a human neuroblastoma cell line on the development of IL- $1 \beta$-mediated prostanoids. Also at extremely low doses, resveratrol has been shown to reduce the development of PGE2 and PGD2 slowly. However, both mPGES1 and COX-2 immune behavior, and COX-1, were not significantly diminished by the same dose of resveratrol. This means that resveratrol enhances the synthesis of the prostanoid without affecting the expression of COX-1, COX-2, or mPGE1 tion (Ramesh et al., 2009). Another research on the role of resveratrol in preventing oxidative stress was performed in SK-N$\mathrm{BE}$, another cell neuroblastoma line. Resveratrol was sirtinolimmune with antioxidant effects on $\mathrm{H}_{2} \mathrm{O}_{2}$ and 6-OHDA, indicating the presence of the activation of the SIRT1 enzymes. The toxicity of the TAT- $\alpha-S y n$ (A30P) and A $\beta 42$ fibrils, both increased by ROS aggregation, was prevented by resveratrol. Resveratrol SIRT1 also lowered the toxicity of A $\beta 42$, affected independent production and stability of $A \beta 42$ fibrous, and reduced the production of intracellular Aß42-dependent ROS (Albani et al., 2009). Further research was done on the role of resveratrol in preventing oxidative stress in SK-N-BE, another cell neuroblastoma group. Sirtinol immune resveratrol with antioxidant effects on $\mathrm{H}_{2} \mathrm{O}_{2}$ and 6-OHDA shows a consequence of the activation of the SIRT1 enzyme. Resveratrol avoided the toxicity caused by TAT- $\alpha$-syn (A30P) and $A \beta 42$ fibrils, which increased the production of ROS. All fibrils were toxic. Resveratrol SirT1 also lowered the toxicity of $A \beta 42$, impacted fibril development and stability independent of $\mathrm{A} \beta 42$, and decreased ROS generation dependent on $\mathrm{A} \beta 42$ (Vingtdeux et al., 2010).

\section{Resveratrol for Other Neurodegenerative Disorders: Therapeutic Agent}

In addition to $\mathrm{AD}$, for example, the neuroprotective activity of resveratrol mentioned above has shown Parkinson's disease (PD) and amyotrophic lateral sclerosis (ALS) to play a significant role. Both antioxidant and anti-inflammatory reactions aid resveratrol as well as SIRT1 and vintage activation, preventing oxygen stress deleterious effects. Resveratrol has recently been shown to be an excellent way of treating these neurological disorders. PD is a neuronal dopaminergic degeneration, which typically entails compacted and PD patients with increased muscle rigidity, restful tremor, bradykinesia, and, worst-case scenario, near-complete circulation loss. Ferretta et al. performed an in vitro experiment to find the effect of resveratrol treatment on primary fibroblast cultures from two patients with early-onset PD linked to different Park2 mutations. Resveratrol has demonstrated the regulation of energy homeostasis through the activation of AMPK and SIRT1 and increases the mitochondrial-oxidative function expression of several PGCla target genes in the mRNA (Ferretta et al., 2014). Lin et al. used a model of PD caused by rotenone in vitro to check the neuroprotective effects of resveratrol. To verify this effect, Lin et al. used in vitro PD models induced with rotenone. Neuroprotection was regulated by resveratrol, which raises both HO- 1 and autophagic flux without affecting cell viability. Consequently, the activities of the HO-1 drug inducer were close to those of resveratrol and healthy against death from rotenone cells (Lin et al., 2014). In the experiment in Khan et al., male rat Wistar has been used to establish a rat model of the pretreated, resveratrol-infected, 6-OHDA-mediated PD. Resveratrol has also been found to suppress COX-2 expression (Khan et al., 2010). Lofrumento et al. have continued investigating the neurosurgical effects of resveratrol on the $\mathrm{PD}$ model of 1.2.3,6-tetrahydropyridine (MPTP) from 1-methyl-4phenyl. Results showed that resveratrol decreases glial, IL- $1 \beta$, IL6 , TNF- $\alpha$, and, respectively, its receptors in mice treated with MPTP SNpc (Lofrumento et al., 2014). Also, AMPK inhibition caused the elimination of the SIRT1 activity and decreased resveratrol protective effects for rotenone-induced apoptosis, which meant that the pathway of AMPK-SIRT1-autophagy in PD cell models played an important function in neuroprotection by resveratrol ( $\mathrm{Wu}$ et al., 2011). Such findings show the effectiveness of resveratrol in PD diagnosis. ALS is a deadly adult neurodegenerative condition characterized by systemic cortex loss, brain stems, and motor neurons of the backbone. For the neuroprotective effects of resveratrol, a classic animal model of ALS was used, namely, the SOD1 transgenic mouse (G93A). Resveratrol has been found in this study to regulate the expression of Sirt1 and PGC1- $\alpha$ and inhibit P53 and its apoptotically downstream lipid peroxidation. Resveratrol delayed the onset of illness significantly, increased life span in the mouse, increased engine neuronal loss, and reduced atrophy and mitochondrial dysfunction. The antioxidant and anti-apoptotic activity of resveratrol is the principal advantage against ALS (Song et al., 2014). Additional work by Mancuso and others, including on resveratrol impact on ALS Mice SOD1 (G93A), has shown that the protective effects of resveratrol are linked to increased sirtuin 1, and the ventricular spinal cord expression of AMPK. Both mediators advocated self-flow standardization and, more specifically, improved SOD1(G93A) (Mancuso et al., 2014). The work of Wang et al. was proven similar to the upregulation of SIRT1, which protects SOD1-mediated toxicity from the ALS cell model (Wang et al., 2011). Both studies were a therapeutic target in ALS patients to prevent the degeneration of motor neurons.

\section{Poor Bioavailability of Resveratrol and Possible Solutions}

We are also confused by its poor bioavailability, given the high bioactivity of resveratrol. Resveratrol plays an important role in $\mathrm{AD}$, particularly in vitro, as we discussed earlier. However, when extended into in vivo animal and human clinical trials, it is 
difficult to demonstrate the same results. To date, the antiinflammatory effects of resveratrol have provided different findings, including some observations that are inconsistent or controversial. Since resveratrol is poorly bioavailable, the level of resveratrol in the target tissues and cells is far from sufficient to prove efficacy in humans. The oral absorbance of resveratrol seemed to be at least 75\%; however, due to the quick and extensive metabolism, biological availability was poor (Walle, 2011). Resveratrol has been rapidly transformed into sulfates and glucuronide metabolites in human liver and intestinal epithelial cells (Anekonda, 2006; Ponzo et al., 2014). Transresveratrol is photosensitive, easily oxidized, and undesirable for pharmacokinetics. The clinical effectiveness of resveratrol is therefore a big concern in drug products and medical technology. Scientists have been searching for analogs and designing new trans-resveratrol delivery mechanisms by coadministering the metabolism of trans-resveratrol inhibitors to improve solubility and bioavailability (Amiot et al., 2013).

Several studies in recent years have been based on new formulation techniques to stabilize and protect resveratrol from decay and improve its solubility to improve its bioavailability, ensure its continuous release, and ultimately transport resveratrol to some places through multi-particular shapes and colloidal carriers. Methylated resveratrol analogs conduct resveratrol-like biological activities. But as the methyl resveratrol analogs are easier to transport and are more resistant to degradation, greater bioavailability is demonstrated. First, Kang and others documented an artificial biosynthesis route to MRC in E. coli culture and two genes for O-methyltransferase along with biosynthetic genes of resveratrol (Kang et al., 2014). Friend et al. developed novel galenic-soluble powder form $(40 \mathrm{mg})$ which was dissolved in a complex mixture of 20 polysorbate and 3-dioleate polyglycerol. Consequently, transresveratrol absorption and complete bioavailability of transresveratrol $(+780 \%)$ were significantly improved by the novel formulation. In two lipid caplets ( $40 \mathrm{mg}$ ), a single dose of soluble trans-resveratrol may increase trans-resveratrol plasma concentrations by 10 times to dry powder type (Amiot et al., 2013). Amri et al. used a monodisperse to operate a porous polymer microsphere to stabilize and maintain resveratrol (Amri et al., 2012). On the other hand, the formulas for achieving a predicted or continuous release of resveratrol were multiparticular shapes in micrometer or colloidal nanometer carriers in specific experiments. Das et al. discovered that pectinate beads (>97.5\%) and $\mathrm{Zn}$ pectinate beads can be used to delay releases that provide the lower gastrointestinal tract with specificity on site (Das et al., 2010; Frozza et al., 2010a and 2010b). It may be a good idea to monitor the release and improve the bioavailability of resveratrol microparticulate systems. Researchers have recently injected resveratrol into the interconnected vanillin chitosan microphones to facilitate stability, and the resveratrol encapsulation effectiveness in microphones was 93.68\% (Peng et al., 2010). In another test, pectin-hardening agents have been developed to connect pectin molecules to zinc ions and glutaraldehyde, with $>94 \%$ encapsulated efficiencies within the colon (Das and Sahoo, 2011). In pharmaceutical applications, cyclodextrins that solve and bind to form polymers are used to supply drugs with hydrophobic drugs. The bioavailability of poorly soluble drugs can be improved, like resveratrol, and the water solubility can be improved by transforming crystal cyclodextrins into amorphous mixtures of isomeric derivatives. Resveratrol was tested in people in an enhanced antioxidant effect as opposed to a transresveratrol formulation only by $\beta$-cyclodextrin-[ $\beta C D-]$ formulation care (Moyano-Mendez et al., 2014). The drug's solubility has been enhanced, and the overall bioavailability of resveratrol nanosuspensions has increased with high pressure and stable nanosuspensions (Kobierski et al., 2009). Solid lipid nanoparticles (SLNs) can be used as an alternative carrier to resveratrol in several studies. Resveratrol solubility, stability, and intracellular loading into SLNs have all been improved (Teskač and Kristl, 2010). The Jose et al. study shows resveratrol-loaded SLNs as well as free resveratrol and SLNs as opposed to free resveratrol may substantially increase the brain concentration for resveratrol. The findings have thus shown that the SLN loaded with resveratrol is a promising therapeutic device in brain tissue (Moyano-Mendez et al., 2014).

A vesicular system, which means colloidal particles and ethosome-concentrated two-plate, which are capable of carrying hydrophilic as well as hydrophobic medicines, is another novel way of providing encapsulated drugs. Vesicular systems can boost bioavailability and have longer term therapeutic activities, including liposomes, transfers, and phytosomes. The formulation of liposomes was selected in a study to optimize the burden of rigid resveratrol and liposome and to improve the bioavailability of pharmaceutical products (Bonechi et al., 2012). Different surfactants and lipids have been used and characterized in terms of thickness, zeta potential, stability, and permeation for the preparation of transferases and ethosome. For preparing resveratrol-laden niosomes, Pangeni et al. used Span 60 and Span 80. This made the latter more stable with a narrow particle distribution and a high trapping efficiency, which demonstrated improved bioavailability (Pangeni et al., 2014). Nanosponges are nanohorizons in nanotechnology for the delivery of drugs. They can be mixed with poorly soluble resveratrol in the substance and increase bioavailability due to their small size and porous nature (Ahmed et al., 2013). Resveratrol encapsulations in $\beta-C D$ nanosponges enhanced their water solubility, and researchers found resveratrol-charged nanosponges feasible for oral and topical delivery systems (Ansari et al., 2010). A lipid-based resveratrol delivery system with the ability to self nanaemulsify Acrysol K 150 as a lipid and Transcutol HP as a surfactant was developed recently by Pund and colleagues. This improved lipid-based nano-emulsifying resveratrol in vitro solubility and in vitro efficiency (Pund et al., 2014).

\section{Resveratrol Clinical Trials in AD}

Resveratrol can benefit in vitro and in vivo assays in the treatment of $\mathrm{AD}$. There is growing evidence. However, until now there has not been a complete large-scale clinical trial; resveratrol is well absorbed, and toxicity is not reported significantly. Resveratrol is not bioavailable, has low water 
solubility, and chemically unstable because of its poor bioavailability (Walle, 2011). Resveratrol was easily metabolized in humans, including a high within $30 \mathrm{~min}$, within $2 \mathrm{~h}$ of oral or intravenous injection of resveratrol (Anekonda, 2006). A number of in vivo experiments in animals and humans showed very poor intestinal absorption, and the identification of unmetabolized resveratrol in the circulating plasma was difficult (Cottart et al., 2010). Upon oral administration of $200 \mathrm{mg}$ three times a day, transresveratrol pharmacokinetics was shown to be independent of age. Nevertheless, trans-resveratrol plasma rates were fairly small (Nunes et al., 2009). Although there is in vivo evidence that resveratrol is bioavailable and bioactive in animal models, definitive results in human trials remain lacking. Several researchers have sought in recent years to find the best ways to treat resveratrol (Amiot et al., 2013). Some work has demonstrated the biological resveratrol metabolites and analogs with identical neuroprotective properties (Saiko et al., 2008). Numerous clinical trials are underway to analyze the effect of resveratrol on neurological diseases, including $\mathrm{AD}$, despite the enormous challenges (Kennedy et al., 2010). The overall concentrations of hemoglobin in the cortex increased significantly during job success in a two-blind cross-checked study of healthy young volunteers who ingested $500 \mathrm{mg}$ of resveratrol (Patel et al., 2011). However, it had no impact on cognitive performance. As a randomized controlled trial (RCT) placebo dietary supplement, 60 patients received a fluid glucose resveratrol/maleate. Up to 1 year after the start of the analysis, the ASD-Cog values were regularly monitored (Mecocci and Polidori, 2012). The ADASCog rating was calculated for six-month period in another multi-intervention trial with mild cognitive impairment, resveratrol, or the caloric limitation or omega-three or placebo addition (Xu et al., 2015). Resveratrol analogs which show better bioavailability, efficacy, and stability than Res are being tested for their activity in relation to many degenerative conditions. Some studies showed that Res derivatives exhibit neuroprotective effects in in vivo and in vitro models (Kim et al., 2007b).

\section{REFERENCES}

Ahmed, R. Z., Patil, G., and Zaheer, Z. (2013). Nanosponges - a completely new nano-horizon: pharmaceutical applications and recent advances. Drug Dev. Ind. Pharm. 39 (9), 1263-1272. doi:10.3109/03639045.2012.694610

Albani, D., Polito, L., Batelli, S., De Mauro, S., Fracasso, C., Martelli, G., et al. (2009). The SIRT1 activator resveratrol protects SK-N-BE cells from oxidative stress and against toxicity caused by $\alpha$-synuclein or amyloid- $\beta$ (1-42) peptide. J. Neurochem. 110 (5), 1445-1456. doi:10.1111/j.1471-4159.2009.06228.x

Allain, H., Bentué-Ferrer, D., Tribut, O., Gauthier, S., Michel, B. F., and Drieu-La Rochelle, C. (2003). Alzheimer's disease: the pharmacological pathway. Fundam. Clin. Pharmacol. 17(4), 419-428. doi:10.1046/j.1472-8206.2003. 00153.x

Alonso, A., Zaidi, T., Novak, M., Grundke-Iqbal, I., and Iqbal, K. (2001). Hyperphosphorylation induces self-assembly of tau into tangles of paired helical filaments/straight filaments. Proc. Natl. Acad. Sci. U.S.A. 98 (12), 6923-6928. doi:10.1073/pnas.121119298

\section{CONCLUDING REMARKS}

Resveratrol (3,4,5-trihydroxystilbene) is a polyphenolic naturally occurring compound that is found in more than 70 species of plants, herbs, or human food material like berries, grapes, and peanuts. It is also beneficial to cure several other diseases like cardiovascular disease, pain, cancer, tissue injury, and inflammation, and also used in $\mathrm{AD}$. Due to its multiple neuroprotection mechanisms, resveratrol is a new agent for treating $\mathrm{AD}$. Because the treatment of $\mathrm{AD}$ remains a global issue, resveratrol therapeutic potential has attracted the researchers' attention. Many studies have been performed in cell culture and in the animal model of $\mathrm{AD}$ to find precise data on the neuroprotective mechanisms of resveratrol. Resveratrol also has beneficial effects on $\mathrm{AD}$ for antioxidant and anti-inflammatory purposes. However, official clinical studies have also been conducted on resveratrol care in AD. While the problems of clinical applications such as bioavailability, dosage, and side effects are enormous, scientists still seek to investigate the comprehensive mechanism and the effective clinical administration of resveratrol.

\section{AUTHOR CONTRIBUTIONS}

MA-D and MHR conceived the original idea and designed the outlines of the study. MHR, RA, TB, SA, MA, and NA-J wrote the draft of the manuscript. MHR, NA, and AA prepared the figures and tables of the manuscript. MHR, OA-E, HE-S, DK, VM, and MA-D performed the literature review and improved the manuscript. All authors contributed to the article and approved.

\section{FUNDING}

The authors extend their appreciation to the Deputyship for Research \& Innovation, "Ministry of Education" in Saudi Arabia for funding this research work through the project number IFKSURP-99

Alonso, A. C., Li, B., Grundke-Iqbal, I., and Iqbal, K. (2008). Mechanism of tauinduced neurodegeneration in Alzheimer disease and related tauopathies. Curr. Alzheimer Res. 5 (4), 375-384. doi:10.2174/156720508785132307

Amiot, M. J., Romier, B., Dao, T. M., Fanciullino, R., Ciccolini, J., Burcelin, R., et al. (2013). Optimization of trans-Resveratrol bioavailability for human therapy. Biochimie. 95 (6), 1233-1238. doi:10.1016/j.biochi.2013.01.008

Amri, A., Chaumeil, J., Sfar, S., and Charrueau, C. (2012). Administration of resveratrol: what formulation solutions to bioavailability limitations? J. Contr. Release. 158 (2), 182-193. doi:10.1016/j.jconrel.2011.09.083

Anekonda, T. S. (2006). Resveratrol--a boon for treating Alzheimer's disease? Brain Res. Rev. 52 (2), 316-326. doi:10.1016/j.brainresrev.2006.04.004

Ansari, A., Rasul, M., Biswas, P., Paul, A., and Rahman, M. (2010). Genectic variability in some maintainer lines of hybrid rice (Oryza sativa L). Bangladesh J. Plant Breed Genet. 23 (2), 35-40. doi:10.3329/bjpbg.v22i2.9085

Ban, J. Y., Cho, S. O., Choi, S. H., Ju, H. S., Kim, J. Y., Bae, K., et al. (2008) Neuroprotective effect of Smilacis chinae rhizome on NMDA-induced neurotoxicity in vitro and focal cerebral ischemia in vivo. J. Pharmacol. Sci. 106 (1), 68-77. doi:10.1254/jphs.fp0071206 
Banerjee, S., Li, Y., Wang, Z., and Sarkar, F. H. (2008). Multi-targeted therapy of cancer by genistein. Canc. Lett. 269 (2), 226-242. doi:10.1016/j.canlet.2008. 03.052

Bastianetto, S., Zheng, W. H., and Quirion, R. (2000). Neuroprotective abilities of resveratrol and other red wine constituents against nitric oxide-related toxicity in cultured hippocampal neurons. Br. J. Pharmacol. 131 (4), 711-720. doi:10. 1038/sj.bjp.0703626

Baur, J. A., Pearson, K. J., Price, N. L., Jamieson, H. A., Lerin, C., Kalra, A., et al. (2006). Resveratrol improves health and survival of mice on a high-calorie diet. Nature., 444 (7117), 337-342. doi:10.1038/nature05354

Baur, J. A., and Sinclair, D. A. (2006). Therapeutic potential of resveratrol: the in vivo evidence. Nat. Rev. Drug Discov. 5 (6), 493-506. doi:10.1038/nrd2060

Beher, D., Wu, J., Cumine, S., Kim, K. W., Lu, S. C., Atangan, L., et al. (2009). Resveratrol is not a direct activator of SIRT1 enzyme activity. Chem. Biol. Drug Des., 74 (6), 619-624. doi:10.1111/j.1747-0285.2009.00901.x

Bonda, D. J., Lee, H. G., Camins, A., Pallàs, M., Casadesus, G., Smith, M. A., et al. (2011). The sirtuin pathway in ageing and Alzheimer disease: mechanistic and therapeutic considerations. Lancet Neurol. 10 (3), 275-279. doi:10.1016/S14744422(11)70013-8

Bonechi, C., Martini, S., Ciani, L., Lamponi, S., Rebmann, H., Rossi, C., et al. (2012). Using liposomes as carriers for polyphenolic compounds: the case of transresveratrol. PLoS One. 7 (8), e41438. doi:10.1371/journal.pone.0041438

Candelario-Jalil, E., de Oliveira, A. C., Gräf, S., Bhatia, H. S., Hüll, M., Muñoz, E., et al. (2007). Resveratrol potently reduces prostaglandin E2 production and free radical formation in lipopolysaccharide-activated primary rat microglia. J. Neuroinflammation. 4 (1), 25-12. doi:10.1186/1742-2094-4-25

Capiralla, H., Vingtdeux, V., Zhao, H., Sankowski, R., Al-Abed, Y., Davies, P., et al. (2012). Resveratrol mitigates lipopolysaccharide- and $A \beta$-mediated microglial inflammation by inhibiting the TLR4/NF-KB/STAT signaling cascade. J. Neurochem. 120 (3), 461-472. doi:10.1111/j.1471-4159.2011.07594.x

Chen, J.-Y., Zhu, Q., Zhang, S., OuYang, D., and Lu, J.-H. (2019). Resveratrol in experimental Alzheimer's disease models: A systematic review of preclinical studies. Pharmocol Res. 150, 104476. doi:10.1016/j.phrs.2019.104476

Cleary, J. P., Walsh, D. M., Hofmeister, J. J., Shankar, G. M., Kuskowski, M. A., Selkoe, D. J., et al. (2005). Natural oligomers of the amyloid-beta protein specifically disrupt cognitive function. Nat. Neurosci. 8 (1), 79-84. doi:10.1038/ nn1372

Cottart, C. H., Nivet-Antoine, V., Laguillier-Morizot, C., and Beaudeux, J. L. (2010). Resveratrol bioavailability and toxicity in humans. Mol. Nutr. Food Res. 54 (1), 7-16. doi:10.1002/mnfr.200900437

Das, M., and Sahoo, S. K. (2011). Epithelial cell adhesion molecule targeted nutlin3a loaded immunonanoparticles for cancer therapy. Acta Biomater. 7, 355-369. doi:10.1016/j.actbio.2010.08.010

Das, S., Ng, K. Y., and Ho, P. C. (2010). Formulation and optimization of zincpectinate beads for the controlled delivery of resveratrol. AAPS PharmSciTech. 11 (2), 729-742. doi:10.1208/s12249-010-9435-7

Dasgupta, B., and Milbrandt, J. (2007). Resveratrol stimulates AMP kinase activity in neurons. Proc. Natl. Acad. Sci. U.S.A. 104 (17), 7217-7222. doi:10.1073/pnas. 0610068104

Feng, Y., and Wang, X. (2012). Antioxidant therapies for Alzheimer's disease. oxidative medicine and cellular longevity. Oxidative Med. Cell. long. 2012, 472932. doi:10.1155/2012/472932

Feng, Y., Wang, X. P., Yang, S. G., Wang, Y. J., Zhang, X., Du, X. T., et al. (2009). Resveratrol inhibits beta-amyloid oligomeric cytotoxicity but does not prevent oligomer formation. Neurotoxicology. 30 (6), 986-995. doi:10.1016/j.neuro. 2009.08.013

Ferretta, A., Gaballo, A., Tanzarella, P., Piccoli, C., Capitanio, N., Nico, B., et al. (2014). Effect of resveratrol on mitochondrial function: implications in parkinassociated familiar Parkinson's disease. Biochim. Biophys. Acta. 1842 (7), 902-915. doi:10.1016/j.bbadis.2014.02.010

Frozza, R. L., Bernardi, A., Paese, K., Hoppe, J. B., da Silva, T., Battastini, A. M., et al. (2010a). Characterization of trans-resveratrol-loaded lipid-core nanocapsules and tissue distribution studies in rats. J. Biomed. Nanotechnol. 6 (6), 694-703. doi:10.1166/jbn.2010.1161

Frozza, R. L., Bernardi, A., Paese, K., Hoppe, J. B., da Silva, T., Battastini, A. M., et al. (2010b). Characterization of trans-resveratrol-loaded lipid-core nanocapsules and tissue distribution studies in rats. J. Biomed. Nanotechnol. 6 (6), 694-703. doi:10.1166/jbn.2010.1161
Ge, J. F., Qiao, J. P., Qi, C. C., Wang, C. W., and Zhou, J. N. (2012). The binding of resveratrol to monomer and fibril amyloid beta. Neurochem. Int. 61 (7), 1192-1201. doi:10.1016/j.neuint.2012.08.012

Gilgun-Sherki, Y., Melamed, E., and Offen, D. (2003). Antioxidant treatment in Alzheimer's disease: current state. J. Mol. Neurosci. 21 (1), 1-11. doi:10.1385/ JMN:21:1:1

Granzotto, A., and Zatta, P. (2011). Resveratrol acts not through anti-aggregative pathways but mainly via its scavenging properties against $A \beta$ and $A \beta$-metal complexes toxicity. PLoS One. 6 (6), e21565. doi:10.1371/journal.pone.0021565

Han, Y. S., Zheng, W. H., Bastianetto, S., Chabot, J. G., and Quirion, R. (2004). Neuroprotective effects of resveratrol against beta-amyloid-induced neurotoxicity in rat hippocampal neurons: involvement of protein kinase C. Br. J. Pharmacol. 141 (6), 997. doi:10.1038/sj.bjp.0705688

Hardy, J. (2006). Alzheimer's disease: the amyloid cascade hypothesis: an update and reappraisal. J Alzheimers Dis. 9 (s3), 151-153. doi:10.3233/jad-2006-9s317

Holland, N., Bolognesi, C., Kirsch-Volders, M., Bonassi, S., Zeiger, E., Knasmueller, S., et al. (2008). The micronucleus assay in human buccal cells as a tool for biomonitoring DNA damage: the HUMN project perspective on current status and knowledge gaps. Mutat. Res. 659 (1-2), 93-108. doi:10.1016/j.mrrev.2008. 03.007

Holtzman, D. M. (2008). Alzheimer's disease: moving towards a vaccine. Nature., 454 (7203), 418-420. doi:10.1038/454418a

Iqbal, K., Liu, F., Gong, C. X., and Grundke-Iqbal, I. (2010). Tau in Alzheimer disease and related tauopathies. Curr. Alzheimer Res. 7 (8), 656-664. doi:10. 2174/156720510793611592

Jahn, H. (2013). Memory loss in Alzheimer's disease. Dialogues Clin. Neurosci. 15 (4), 445. doi:10.31887/DCNS.2013.15.4/hjahn

Jang, J. H., and Surh, Y. J. (2003). Protective effect of resveratrol on beta-amyloidinduced oxidative PC12 cell death. Free Radic. Biol. Med. 34 (8), 1100-1110. doi:10.1016/s0891-5849(03)00062-5

Jeon, B. T., Jeong, E. A., Shin, H. J., Lee, Y., Lee, D. H., Kim, H. J., et al. (2012). Resveratrol attenuates obesity-associated peripheral and central inflammation and improves memory deficit in mice fed a high-fat diet. Diabetes. 61 (6), 1444-1454. doi:10.2337/db11-1498

Kang, S. Y., Lee, J. K., Choi, O., Kim, C. Y., Jang, J. H., Hwang, B. Y., et al. (2014). Biosynthesis of methylated resveratrol analogs through the construction of an artificial biosynthetic pathway in E. coli. BMC Biotechnol. 14 (1), 67. doi:10. 1186/1472-6750-14-67

Kelley, B. J., and Petersen, R. C. (2007). Alzheimer's disease and mild cognitive impairment. Neurol. Clin. 25 (3), 577-609,v. doi:10.1016/j.ncl.2007.03.008

Kennedy, D. O., Wightman, E. L., Reay, J. L., Lietz, G., Okello, E. J., Wilde, A., et al. (2010). Effects of resveratrol on cerebral blood flow variables and cognitive performance in humans: a double-blind, placebo-controlled, crossover investigation. Am. J. Clin. Nutr. 91(6), 1590-1597. doi:10.3945/ajcn.2009.28641

Khan, M. M., Ahmad, A., Ishrat, T., Khan, M. B., Hoda, M. N., Khuwaja, G., et al. (2010). Resveratrol attenuates 6-hydroxydopamine-induced oxidative damage and dopamine depletion in rat model of Parkinson's disease. Brain Res. 1328, 139-151. doi:10.1016/j.brainres.2010.02.031

Kim, D., Nguyen, M. D., Dobbin, M. M., Fischer, A., Sananbenesi, F., Rodgers, J. T., et al. (2007a). SIRT1 deacetylase protects against neurodegeneration in models for Alzheimer's disease and amyotrophic lateral sclerosis. EMBO J. 26 (13), 3169-3179. doi:10.1038/sj.emboj.7601758

Kim, H. J., Lee, K. W., and Lee, H. J. (2007b). Protective effects of piceatannol against beta-amyloid-induced neuronal cell death, Ann. N. Y. Acad. Sci. 1095 (1), 473-482. doi:10.1196/annals.1397.051

Kim, J., Lee, H. J., and Lee, K. W. (2010). Naturally occurring phytochemicals for the prevention of Alzheimer's disease. J. Neurochem. 112 (6), 1415-1430. doi:10.1111/j.1471-4159.2009.06562.x

Kim, Y., Lim, S. Y., Rhee, S. H., Park, K. Y., Kim, C. H., Choi, B. T., et al. (2006). Resveratrol inhibits inducible nitric oxide synthase and cyclooxygenase-2 expression in beta-amyloid-treated C6 glioma cells. Int. J. Mol. Med. 17 (6), 1069-1075. doi:10.1002/dvdy.20894

Kobierski, S., Ofori-Kwakye, K., Müller, R., and Keck, C. (2009). Resveratrol nanosuspensions for dermal application--production, characterization, and physical stability. Pharmazie. 64 (11), 741-747. doi:10.1691/ph.2009.9097

Kores, K., Lešnik, S., Bren, U., Janežič, D. A., and Konc, J. (2019). Discovery of novel potential human targets of resveratrol by inverse molecular docking. J chem Inf Model. 59 (5), 2467-2478. doi:10.1021/acs.jcim.8b00981 
Kumar, A., Naidu, P., Seghal, N., and Padi, S. (2007). Neuroprotective effects of resveratrol against intracerebroventricular colchicine-induced cognitive impairment and oxidative stress in rats. Pharmacology. 79 (1), 17-26. doi:10.1159/000097511

Kumar, P., Padi, S. S., Naidu, P. S., and Kumar, A. (2006). Effect of resveratrol on 3nitropropionic acid-induced biochemical and behavioural changes: possible neuroprotective mechanisms. Behav. Pharmacol. 17 (5-6), 485-492. doi:10. 1097/00008877-200609000-00014

Kwon, K. J., Kim, H. J., Shin, C. Y., and Han, S. H. (2010). Melatonin potentiates the neuroprotective properties of resveratrol against beta-amyloid-induced neurodegeneration by modulating AMP-activated protein kinase pathways. J. Clin. Neurol. 6 (3), 127-137. doi:10.3988/jcn.2010.6.3.127

Ladiwala, A. R., Lin, J. C., Bale, S. S., Marcelino-Cruz, A. M., Bhattacharya, M., Dordick, J. S., et al. (2010). Resveratrol selectively remodels soluble oligomers and fibrils of amyloid Abeta into off-pathway conformers. J. Biol. Chem. 285 (31), 24228-24237. doi:10.1074/jbc.M110.133108

Lagouge, M., Argmann, C., Gerhart-Hines, Z., Meziane, H., Lerin, C., Daussin, F., et al. (2006). Resveratrol improves mitochondrial function and protects against metabolic disease by activating SIRT1 and PGC-1alpha. Cell. 127 (6), 1109-1122. doi:10.1016/j.cell.2006.11.013

Lee, E. O., Park, H. J., Kang, J. L., Kim, H. S., and Chong, Y. H. (2010). Resveratrol reduces glutamate-mediated monocyte chemotactic protein-1 expression via inhibition of extracellular signal-regulated kinase $1 / 2$ pathway in rat hippocampal slice cultures. J. Neurochem. 112 (6), 1477-1487. doi:10.1111/j. 1471-4159.2009.06564.x

Li, F., Gong, Q., Dong, H., and Shi, J. (2012). Resveratrol, a neuroprotective supplement for Alzheimer's disease. Curr. Pharmaceut. Des. 18 (1), 27-33. doi:10.2174/138161212798919075

Lin, T. K., Chen, S. D., Chuang, Y. C., Lin, H. Y., Huang, C. R., Chuang, J. H., et al. (2014). Resveratrol partially prevents rotenone-induced neurotoxicity in dopaminergic SH-SY5Y cells through induction of heme oxygenase-1 dependent autophagy. Int. J. Mol. Sci. 15 (1), 1625-1646. doi:10.3390/ ijms 15011625

Lofrumento, D. D., Nicolardi, G., Cianciulli, A., De Nuccio, F., La Pesa, V., Carofiglio, V., et al. (2014). Neuroprotective effects of resveratrol in an MPTP mouse model of Parkinson's-like disease: possible role of SOCS-1 in reducing pro-inflammatory responses. Innate Immun. 20 (3), 249-260. doi:10. $1177 / 1753425913488429$

Ma, X., Sun, Z., Han, X., Li, S., Jiang, X., Chen, S., et al. (2019). Neuroprotective effect of resveratrol via activation of Sirt1 signaling in a rat model of combined diabetes and Alzheimer's disease. Front Neurosci. 13, 1400. doi:10.3389/fnins. 2019.01400

Mallucci, G. R., White, M. D., Farmer, M., Dickinson, A., Khatun, H., Powell, A. D., et al. (2007). Targeting cellular prion protein reverses early cognitive deficits and neurophysiological dysfunction in prion-infected mice. Neuron. 53 (3), 325-335. doi:10.1016/j.neuron.2007.01.005

Mancuso, R., Del Valle, J., Modol, L., Martinez, A., Granado-Serrano, A. B., Ramirez-Núñez, O., et al. (2014). Resveratrol improves motoneuron function and extends survival in SOD1(G93A) ALS mice. Neurotherapeutics. 11 (2), 419-432. doi:10.1007/s13311-013-0253-y

Marambaud, P., Zhao, H., and Davies, P. (2005). Resveratrol promotes clearance of Alzheimer's disease amyloid-beta peptides. J. Biol. Chem. 280 (45), 37377-37382. doi:10.1074/jbc.M508246200

McGeer, E. G., and McGeer, P. L. (2003). Inflammatory processes in Alzheimer's disease. Prog. Neuro-Psychopharmacol. Biol. Psychiatry. 27 (5), 741-749. doi:10. 1016/S0278-5846(03)00124-6

Mecocci, P., and Polidori, M. C. (2012). Antioxidant clinical trials in mild cognitive impairment and Alzheimer's disease. Biochim. Biophys. Acta. 1822 (5), 631-638. doi:10.1016/j.bbadis.2011.10.006

Moyano-Mendez, J. R., Fabbrocini, G., De Stefano, D., Mazzella, C., Mayol, L., Scognamiglio, I., et al. (2014). Enhanced antioxidant effect of transresveratrol: potential of binary systems with polyethylene glycol and cyclodextrin. Drug Dev. Ind. Pharm. 40 (10), 1300-1307.doi:10.3109/ 03639045.2013.817416

Nunes, T., Almeida, L., Rocha, J. F., Falcão, A., Fernandes-Lopes, C., Loureiro, A. I., et al. (2009). Pharmacokinetics of trans-resveratrol following repeated administration in healthy elderly and young subjects. J. Clin. Pharmacol. 49 (12), 1477-1482. doi:10.1177/0091270009339191
Nunomura, A. (2013). Oxidative stress hypothesis for Alzheimer's disease and its potential therapeutic implications. Rinsho Shinkeigaku. 53 (11), 1043-1045. doi:10.5692/clinicalneurol.53.1043

Oomen, C. A., Farkas, E., Roman, V., Van Der Beek, E. M., Luiten, P. G., and Meerlo, P. (2009). Resveratrol preserves cerebrovascular density and cognitive function in aging mice. Front. Aging Neurosci. 1, 4. doi:10.3389/neuro.24.004.2009

Pangeni, R., Sahni, J. K., Ali, J., Sharma, S., and Baboota, S. (2014). Resveratrol: review on therapeutic potential and recent advances in drug delivery. Expet Opin. Drug Deliv. 11 (8), 1285-1298. doi:10.1517/17425247.2014.919253

Pasinetti, G. M., Wang, J., Marambaud, P., Ferruzzi, M., Gregor, P., Knable, L. A., et al. (2011). Neuroprotective and metabolic effects of resveratrol: therapeutic implications for Huntington's disease and other neurodegenerative disorders. Exp. Neurol. 232 (1), 1-6. doi:10.1016/j.expneurol.2011.08.014

Patel, K. R., Scott, E., Brown, V. A., Gescher, A. J., Steward, W. P., and Brown, K. (2011). Clinical trials of resveratrol. Ann. N. Y. Acad. Sci. 1215 (1), 161-169. doi:10.1111/j.1749-6632.2010.05853.x

Peng, H., Xiong, H., Li, J., Xie, M., Liu, Y., Bai, C., et al. (2010). Vanillin cross-linked chitosan microspheres for controlled release of resveratrol. Food Chem. 121 (1), 23-28. doi:10.1016/j.foodchem.2009.11.085

Perl, D. P. (2010). Neuropathology of Alzheimer's disease. Mt. Sinai J. Med. 77 (1), 32-42. doi: $10.1002 / \mathrm{msj} .20157$

Ponzo, V., Soldati, L., and Bo, S. (2014). Resveratrol: a supplementation for men or for mice?. J. Transl. Med. 12, 158. doi:10.1186/1479-5876-12-158

Pund, S., Thakur, R., More, U., and Joshi, A. (2014). Lipid based nanoemulsifying resveratrol for improved physicochemical characteristics, in vitro cytotoxicity and in vivo antiangiogenic efficacy. Colloids Surf. B Biointerfaces. 120, 110-117. doi:10.1016/j.colsurfb.2014.05.016

Rahvar, M., Nikseresht, M., Shafiee, S. M., Naghibalhossaini, F., Rasti, M., Panjehshahin, M. R., et al. (2011). Effect of oral resveratrol on the BDNF gene expression in the hippocampus of the rat brain. Neurochem. Res. 36 (5), 761-765. doi:10.1007/s11064-010-0396-8

Ramesh, G., Borda, J. T., Gill, A., Ribka, E. P., Morici, L. A., Mottram, P., et al. (2009). Possible role of glial cells in the onset and progression of Lyme neuroborreliosis. J. Neuroinflammation. 6 (1), 23. doi:10.1186/1742-2094-6-23

Roberson, E. D., and Mucke, L. (2006). 100 years and counting: prospects for defeating Alzheimer's disease. Science. 314 (5800), 781-784. doi:10.1126/ science.1132813

Saiko, P., Szakmary, A., Jaeger, W., and Szekeres, T. (2008). Resveratrol and its analogs: defense against cancer, coronary disease and neurodegenerative maladies or just a fad? Mutat. Res. 658 (1-2), 68-94. doi:10.1016/j.mrrev. 2007.08.004

Schmatz, R., Mazzanti, C. M., Spanevello, R., Stefanello, N., Gutierres, J., Corrêa, M., et al. (2009). Resveratrol prevents memory deficits and the increase in acetylcholinesterase activity in streptozotocin-induced diabetic rats. Eur. J. Pharmacol. 610 (1-3), 42-48. doi:10.1016/j.ejphar.2009.03.032

Selkoe, D. J. (2001). Alzheimer's disease: genes, proteins, and therapy. Physiol. Rev. 81 (2), 741-766. doi:10.1152/physrev.2001.81.2.741

Selkoe, D. J. (2002). Alzheimer's disease is a synaptic failure. Science. 298 (5594), 789-791. doi:10.1126/science.1074069

Sharma, M., and Gupta, Y. (2002). Chronic treatment with trans resveratrol prevents intracerebroventricular streptozotocin induced cognitive impairment and oxidative stress in rats. Life Sci. 71 (21), 2489-2498. doi:10. 1016/s0024-3205(02)02083-0

Song, L., Chen, L., Zhang, X., Li, J., and Le, W. (2014). Resveratrol ameliorates motor neuron degeneration and improves survival in SOD1(G93A) mouse model of amyotrophic lateral sclerosis. BioMed Res. Int. 2014, 483501. doi:10. $1155 / 2014 / 483501$

Spanier, G., Xu, H., Xia, N., Tobias, S., Deng, S., Wojnowski, L., et al. (2009). Resveratrol reduces endothelial oxidative stress by modulating the gene expression of superoxide dismutase 1 (SOD1), glutathione peroxidase 1 (GPx1) and NADPH oxidase subunit (Nox4). J. Physiol. Pharmacol. 60 (Suppl 4), 111-116.

Tansey, M. G., McCoy, M. K., and Frank-Cannon, T. C. (2007). Neuroinflammatory mechanisms in Parkinson's disease: potential environmental triggers, pathways, and targets for early therapeutic intervention. Exp. Neurol. 208 (1), 1-25. doi:10.1016/j.expneurol.2007.07.004

Teskač, K., and Kristl, J. (2010). The evidence for solid lipid nanoparticles mediated cell uptake of resveratrol. Int. J. Pharm. 390 (1), 61-69. doi:10.1016/j.jpharm.2009.10.011 
Velez-Pardo, C., Ospina, G. G., and del Rio, M. J. (2002). A $\beta$ [25-35] peptide and iron promote apoptosis in lymphocytes by an oxidative stress mechanism: involvement of $\mathrm{H} 2 \mathrm{O} 2$, caspase-3, NF- $\mathrm{B}$, p53 and c-Jun. Neurotoxicology. 23 (3), 351-365. doi:10.1016/s0161-813x(02)00081-5

Villaflores, O. B., Chen, Y. J., Chen, C. P., Yeh, J. M., and Wu, T. Y. (2012). Curcuminoids and resveratrol as anti-Alzheimer agents. Taiwan. J. Obstet. Gynecol. 51 (4), 515-525. doi:10.1016/j.tjog.2012.09.005

Vingtdeux, V., Giliberto, L., Zhao, H., Chandakkar, P., Wu, Q., Simon, J. E., et al. (2010). AMP-activated protein kinase signaling activation by resveratrol modulates amyloid-beta peptide metabolism. J. Biol. Chem. 285 (12), 9100-9113. doi:10.1074/jbc.M109.060061

Walle, T.. (2011). Bioavailability of resveratrol. Ann. N. Y. Acad. Sci. 1215 (1), 9-15.doi:10.1111/j.1749-6632.2010.05842.x

Wang, J., Ho, L., Zhao, W., Ono, K., Rosensweig, C., Chen, L., et al. (2008). Grape-derived polyphenolics prevent Abeta oligomerization and attenuate cognitive deterioration in a mouse model of Alzheimer's disease. J. Neurosci. 28 (25), 6388-6392. doi:10.1523/JNEUROSCI.0364-08.2008

Wang, J., Ho, L., Zhao, Z., Seror, I., Humala, N., Dickstein, D. L., et al. (2006). Moderate consumption of Cabernet Sauvignon attenuates Abeta neuropathology in a mouse model of Alzheimer's disease. Faseb. J. 20 (13), 2313-2320. doi:10.1096/fj.06-6281com

Wang, J., Zhang, Y., Tang, L., Zhang, N., and Fan, D. (2011). Protective effects of resveratrol through the up-regulation of SIRT1 expression in the mutant hSOD1-G93A-bearing motor neuron-like cell culture model of amyotrophic lateral sclerosis. Neurosci. Lett. 503 (3), 250-255. doi:10.1016/j.neulet.2011. 08.047

Wilcock, D. M., Gharkholonarehe, N., Van Nostrand, W. E., Davis, J., Vitek, M. P., and Colton, C. A. (2009). Amyloid reduction by amyloid-beta vaccination also reduces mouse tau pathology and protects from neuron loss in two mouse models of Alzheimer's disease. J. Neurosci. 29 (25), 7957-7965. doi:10.1523/ JNEUROSCI.1339-09.2009

Wu, Y., Li, X., Zhu, J. X., Xie, W., Le, W., Fan, Z., et al. (2011). Resveratrol-activated AMPK/SIRT1/autophagy in cellular models of Parkinson's disease. Neurosignals. 19 (3), 163-174. doi:10.1159/000328516

Xu, W., Tan, L., Wang, H. F., Jiang, T., Tan, M. S., Tan, L., et al. (2015). Metaanalysis of modifiable risk factors for Alzheimer's disease. J. Neurol. Neurosurg. Psychiatry. 86 (12), 1299-1306. doi:10.1136/jnnp-2015-310548

Yaffe, K.. (2010). Treatment of Alzheimer disease and prognosis of dementia: time to translate research to results. Jama. 304 (17), 1952-1953. doi:10.1001/jama.2010.1625

Yan, Y., Yang, H., Xie, Y., Ding, Y., Kong, D., and Yu, H. J. N. R. (2020). Research progress on Alzheimer's disease and resveratrol. Neurochem Res. 45 (5), 989-1006. doi:10.1007/s11064-020-03007-0

Zhang, F., Liu, J., and Shi, J. S. (2010). Anti-inflammatory activities of resveratrol in the brain: role of resveratrol in microglial activation. Eur. J. Pharmacol. 636 (1-3), 1-7. doi:10.1016/j.ejphar.2010.03.043

Conflict of Interest: The authors declare that the research was conducted in the absence of any commercial or financial relationships that could be construed as a potential conflict of interest.

Copyright (C) 2020 Rahman, Akter, Bhattacharya, Abdel-Daim, Alkahtani, Arafah, Al-Johani, Alhoshani, Alkeraishan, Alhenaky, Abd-Elkader, El-Seedi, Kaushik and Mittal. This is an open-access article distributed under the terms of the Creative Commons Attribution License (CC BY). The use, distribution or reproduction in other forums is permitted, provided the original author(s) and the copyright owner(s) are credited and that the original publication in this journal is cited, in accordance with accepted academic practice. No use, distribution or reproduction is permitted which does not comply with these terms. 